\title{
The Link between Transformational Leadership Traits and Corporate Culture Types: The Prerequisites for Sustainable Performance in Public and Private Sectors Organizations
}

\author{
Paul L. Flemming ${ }^{1}$, Barbara E. Flemming ${ }^{1}$ \\ ${ }^{1}$ School of Business, University of the Virgin Islands, USA \\ Correspondence: Paul L. Flemming, School of Business, University of the Virgin Islands, USA. \\ Received: February 16, 2017 \\ Accepted: February 28, 2017 \\ Online Published: March 1, 2017 \\ doi:10.11114/bms.v3i1.2255 \\ URL: https://doi.org/10.11114/bms.v3i1.2255
}

\begin{abstract}
This study has investigated the link between transformational leadership styles, corporate organizational culture types and performance in four public sector organizations. The objective of this research was to examine the effect of individual leadership traits, and culture types on performance in public organizations there by validating the arguments made by scholars and practitioners that organizational performance is more evident in private sector corporations. The behavior elements examined in this study were idealized influence behavior, inspirational motivation, intellectual stimulation, individualized consideration, idealized influence and effectiveness. The cultural variables used were clan culture, adhocracy culture, market culture, and hierarchal culture. This study utilized a survey designed and implemented a quantitative methodology. The analysis used primary data produced by the Multifactor Leadership Questionnaire (MLQ) to administer on 200 respondents from four of the largest public sector organizations in the United State Virgin Islands to examine the relationship of transformational leadership, organizational performance and corporate organizational culture. The responses were scaled and coded to enable the segmentation of the data into dependent and independent variables based on the leadership, performance and culture variables. The study utilized the multiple regression models and correlation statistical analyses to determine the degree of commonality among the components. The study concluded that transformational leadership and corporate organizational culture have positive effects on facilitating performance and is best suited in managing change and innovation in mature public and private sector organizations.
\end{abstract}

Keyword: transformational leadership, organizational culture, performance

\section{Introduction}

Researchers have argued that it was not until the 1980s that organizational scholars began to pay serious attention to the concept of organizational leadership and corporate culture. Corporate organizational culture (or corporate culture), however, has been an area in which conceptual research and scholarship have provided beneficial gains for managers as they search for alternative ways to improve their organizational performance or effectiveness (Bass, 2003; Cameron \& Quinn, 2006). Cameron and Quinn (2006) asserted that there is a need for leaders to constantly evaluate their strategic position and align the organization's overall mission, goals and objectives with a philosophical purpose for the continued existence of the organization. It was further argued that there is a tremendous level of uncertainty associated with static organizations, given the high levels of unpredictability that currently exists in the global economy. The inability to effectively predict the future as it relates to organizational functionality, both in the public and private sectors, has given rise to a number of concerns relating to the future direction and stability of these organizations. Another dilemma that has been argued by scholars is the ability to effectively define an organization's framework and diagnosed the contributions that organizational leadership and culture make on a firm's performance (Bass \& Avolio, 2002; Cameron \& Quinn, 2006; Kouzes \& Posner, 2003).

This study seeks to validate the link between the leadership-culture phenomenons and assess the impact on organizational performance. Researchers in the field of social sciences are of the conclusive opinion that is it imperative to expand the body of knowledge, by developing a model of leadership style and understanding its association with a given organizational culture framework, will improve management's ability to diagnose the compatibility between its leaders and the firm's culture. Further, aligning an organization specific environment with the optimum leadership style will 
significantly maximize the leader's effectiveness and enhance the organizational performance. Understanding the dynamics associated with leadership and culture will enable the organizations to acquire new knowledge in designing and restructuring their internal environment, selecting their human resources, and improving the organizational effectiveness. As Schimmoeller (2006) asserted, it is imperative that an organization understands its specific culture types and recognize which type of leadership style best matches the organization's culture for successful transition to occur. Thus, the purpose of this study was to determine if there is any relationship that exists between transformational leadership traits and corporate organizational culture types in public and private sector organizations. The research drew parallels by reviewing literature relating to leadership in the public and private sectors, specifically, the transformational leadership literature that is primarily concerned with the capabilities required to enact organizational performance successfully.

\section{Literature}

\subsection{Transformational Leadership and Corporate Organizational Culture}

The concept of transformational leadership and organizational culture have been studied extensively over the past decade given the argument that the combination of both phenomena hold great promise for advancing organizational effectiveness (Banerji \& Krishnan, 2000; Bass \& Avoilo, 2005). Bass (2003) purported that the constructs of transformational leadership would facilitate follower's performance as a consequence of leader's influence. The underlying framework represented the rising awareness of the traits of transformational leadership and their importance and value in developing idealized influence behaviour, inspirational motivation, intellectual stimulation, individualized consideration and idealized influence attributes in their followers to transcend their own personal ambition for a unified collective purpose, mission or vision for their organization (Blackwell, 2006).

Additionally, Bass (2003) argued that transformational leaders act as role models for their followers, motivate and inspire followers through team efforts, challenge and stimulate their followers intellectually, and facilitate personal development and growth in their followers. Schimmoeller (2006) articulated that transformational leaders may be more effective in aligning organizations' philosophical objectives with their expected performances, when compared to transactional leaders whose influences are impacted by contract terms with their followers. Transformational leadership and organizational culture have been argued to be tightly intertwined (Schein, 2002). Leaders are required to have an understanding of the organization's culture types within its internal environment if they wish to communicate and implement a clear vision for the future of the organization. Transformational leaders have the potential to shape and maintain organizations culture which may facilitate organizational effectiveness in private sector organizations (Louis, Linnenluecke \& Griffith, 2009). Consistent with the potential contribution of transformational leadership in transforming organizations, Cameron and Quinn (2006) postulated the argument that most organizational scholars and observers now recognized that organizational culture has a powerful effect on the performance and the long-term effectiveness of organizations. However, Lim, (2006) argued that it was not until the 1980s that organizational scholars began to pay serious attention to the concept of culture. Organizational culture, however, has been an area in which conceptual research and scholarship have provided beneficial gains for managers as they search for alternative ways to improve their organizational effectiveness. Research has found that organizational culture can have serious impact on the organizational leadership and can smooth the route towards achieving organizational goals (Riasi and Aasdzadeh, 2015). In other words, a favorable organizational culture enables the leaders to handle the conflicts more effectively and focus their attention on their primary objectives (Riasi and Aasdzadeh, 2015).

It was further argued that empirical research has produced a compelling array of findings demonstrating the importance of culture to enhance organizational performance (Nahavandi, 2006). However, the reason why organizational culture was practically ignored as an important phenomenon in accounting for organizational performance is the conceptualization that both managers and leaders took for granted the prevailing values, underlying assumptions, expectations, collective memories, and philosophical beliefs present within an organization (hooijberg, \& Petrock, 2004). Nevertheless, to effectively assess the relationship of culture with leadership in enhancing performance, four culture types were evaluated, namely: clan culture leadership role; hierarchy culture leadership role; adhocracy culture leadership role; and market culture leadership role (Cameron \& Quinn, 2006). If an organizational skill profile is not adequately aligned with its culture, business strategy or major policy initiatives, there can be significant repercussions that can negatively impact effective performance and lead to dysfunctional structures within the organizational internal and external environments (Cameron \& Quinn, 2006).

\subsection{Transformational Leadership Traits}

Transformational leadership is a process that changes and transforms followers. It focuses on individual's emotions, values, ethics, standards, and long-term goals. The theory suggests that some leaders, through their personal traits and their relationships with followers, go beyond a simple exchange of resources and productivity but seek to develop and empower individuals to their fullest potential (Nahavandi, 2006 ). The traits of transformational leadership theory can be 
employed to influence followers on an individual and group level, and it can also be instrumental in influencing an entire organization and its culture. To fully conceptualize the contributions of transformational leadership theory, it is important to review each theory's contribution to organizational development.

\subsection{Idealized Influence}

As depicted in the transformational leadership framework in figure 1, charisma or idealized influence describes leaders who act as strong role-models for followers, and whom followers seek to emulate. These leaders have very high standards of conduct, moral principles and ethical values (Aronson, 2001). They also provide their followers with a clear vision and a mission for their organizations and, in turn, earn a high degree of respect and trust by their followers (Bass \& Avolio, 2003; Bass, 2003; Cooper \& Schindler, 2006 \&; Nahavandi, 2006).

\subsection{Inspiration Motivation}

The second factor in the transformational leadership framework is inspirational motivation. This factor articulates the importance of leaders communicating high expectations to followers, inspiring and motivating them by providing meaning and challenge to their followers' work so that they can develop a shared vision in the organization (Bass \& Avolio, 2007, Campbell \& Freeman, 2013; Kouzes \& Posner, 2003). Further, the inspirational appeal of transformational leaders brings out the best efforts in followers such as harmony, charity and good works. The leader develops team spirit in followers who in turn display enthusiasm and optimism in achieving organizational goals (Barbuto, 2005; Avolio, Waldman, \& Yammarino, 2004).

\subsection{Intellectual Stimulation}

Avolio, Bass, \& Jung (2003) argued that the intellectual stimulation factor of transformational leadership "incorporates an open architecture dynamic into a process of situation evaluation, vision formulation and patterns of implementation" ( $p$. 6). However, by inspiring a shared vision, leaders encourage followers to view problems from different perspectives in order to develop new solutions. The charismatic bond provides support and encouragement for followers and prevents them from feeling isolated. Intellectual stimulation is also exhibited when the leader facilitates the efforts of followers to become more innovative and creative by questioning assumptions, reframing problems, and developing new strategies to resolve organizational challenges. The transformational leader facilitates individuals' attempts in developing new initiatives, and there is no public criticism of individual's mistakes even though they differ from their leaders' ideas (Black, 2003; Tucker \& Russell, 2004).

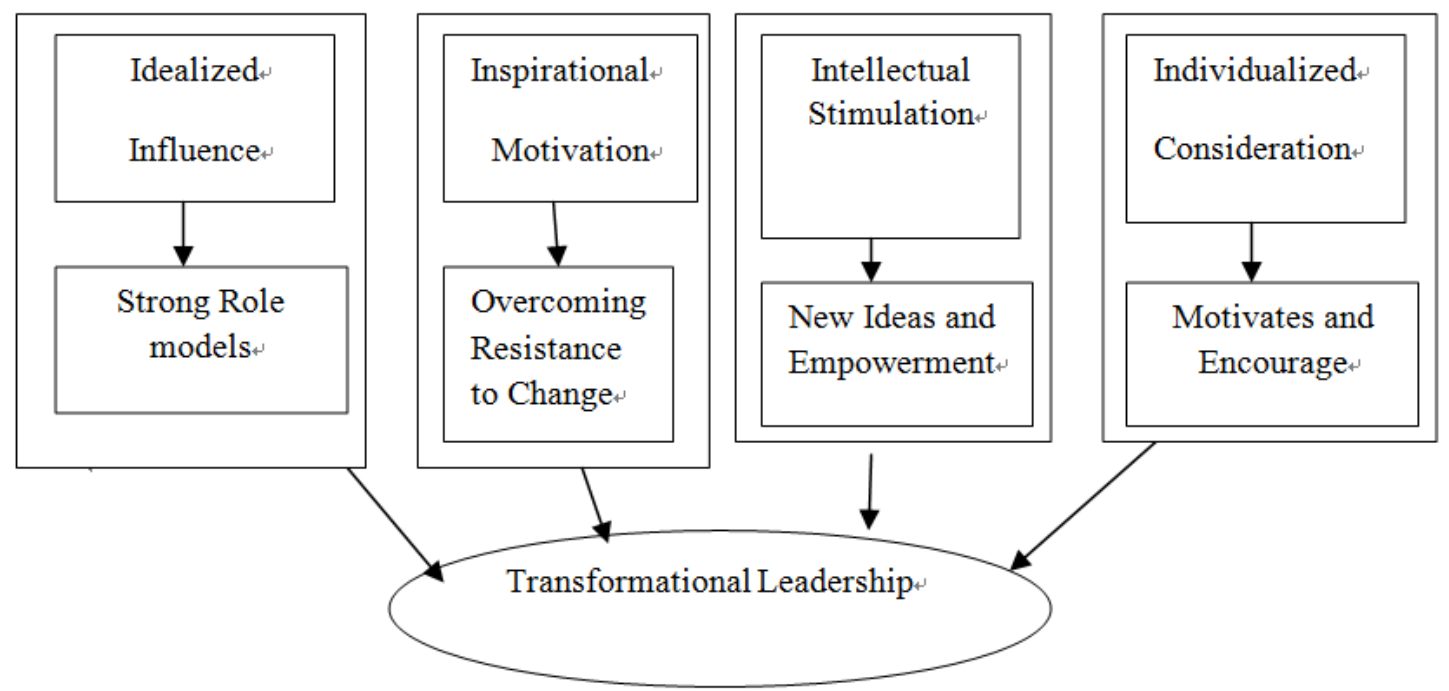

Figure 1. Model 1: Transformational Leadership Factors

\subsection{Individualized Consideration}

The individualized consideration factor is representative of the leader who provides a supportive climate in which he / she listened to the individual needs of the follower. The transformational leader treats followers with respect and facilitate individual growth by providing coaching, mentoring and growth opportunities (Bass \& Avolio, 2003; Bass \& Burnes, 2003). The leader may utilize a variety of methodologies such as delegation to help followers accomplish their tasks and grow through personal challenges in the organization. Finally, like the other leadership models and theories examined by scholars and practitioners, it is prudent to present the arguments in support of the strengths and weaknesses of transformational leadership. First, proponents (Northouse, 2004) argued that transformational leadership has been widely 
researched from many different perspectives by prominent leaders both in the public and private sectors, since its inception in the 1970s. Northouse (2004) noted that an analysis of all the articles published in the Leadership Quarterly over the past decade showed that $34 \%$ of the articles were about transformational /charismatic leadership; and well over 200 theses, dissertations, and research projects were conducted using transformational leadership. Second, transformational leadership has intuitive appeal. This leadership style describes the aggressive approach leaders take in advocating change for others, and this concept brings to fruition the dynamic personalities society associate with leadership (Howell \&Avolio, 2006). Third, transformational leadership treats leadership like a process that occurs between followers and leaders (Kotter \& Heskette, 2004; Northouse, 2004). The fact that the process incorporates the leaders' and the follower's needs, transformational leadership is considered a shared process that emerges from a symbiotic relationship between leader and follower.

\subsection{Corporate Organizational Culture}

Parry (2012) asserted that the concept of organizational culture has created ongoing research into the behavioral sciences of organizations' performances, and scientists from the field of anthropology and sociology have been studying the impact of culture on organizational effectiveness for many years. The arguments postulated by Ogbonna \& Harris, 2000) asserted that organizational culture is an abstract and complex phenomenon. As a result, scholars in organizational behavior (Parry, 2012; Rowden, 2002) presented research findings demonstrating the importance of organizational culture. One such findings view organizational culture as observable traits focusing on the physical characteristics of the organization such as architecture, artwork, dress patterns, language, stories, myths, behavior, formal rules, rituals, ceremonies, and appearances. Other researchers argued that the physical characteristics are not culture types; rather they are the symbolic constructs of the unobservable characteristics of culture such as the norms, beliefs, assumptions, ideologies, values and shared perceptions held by members of the organizations (Nahavandi, 2006; Robbins, 1995; Yuki, 2002).

According to Howard (2009) and Robbins (2005), an organization's culture constantly changes as the organization itself changes. These changing dynamics of the organization contribute to the formations of its culture as seen through the reflective lenses of four leading scholars (Fombrun, 2011; Schein, 2002; Selden\& Sowa 2004). Schein (2002) argued that organizational culture forms at three levels of abstraction: assumptions, values, and artifacts. Schein (2002) asserted that the core of organizational culture exists in the basic assumptions that individuals share regarding such things as human nature, social relationships, and relations among social institutions and their environments. These philosophical assumptions are abstract in nature, exist in the subconscious minds of people, and are often taken for granted by organization's leaders (Howard, 2009). However, Robbins (2005) pointed out that the issues of dependency and authority must be factored into the paradigm of culture development, which is the focal point of cultural formation, by clearly articulating the role of the leadership in organizations. The leader selected is indicative of many values and norms of the group or organization. The second level of cultural formation is the level of values (Schein (2002). Values represent the integrity and moral fortitude that organizational members display regarding the nature of transactions and the manner in which the rules governing these transactions are upheld (Cameron \& Quinn, 2006; Howard, 2009).

On the contrary, Scott \& Davis (2007) typology of culture formation represents a complex phenomenon and argued that organizational culture exists along three dimensions: an evolutionary dimension, an internal dimension, and an external dimension. An analysis of Scott \& Davis (2007) typology bears some relevance of Schein's (2002) view in which he postulated that culture develops over time in a series of stages. However, Scholz (2002) presented five evolutionary stages - stable, reaction, anticipating, exploring, and the creative stages - which show how the organization responds to culture challenges. According to Scholz (2003), in the stable stage no changes are contemplated; while the reactive stage shows acceptance to minimal changes. In the anticipating stage, incremental changes are accepted; compared to the exploring and creative stages where large amounts of changes are possible and continuous. Additionally, while the internal dimension of culture addresses issues relating to the conditions operating within the organization that affect the culture, the external dimension of culture focuses on the external environment. Thus, an organization facing a complex and dynamic environment is likely to develop culture that is flexible, innovative, and risk-taking (Robbins, 2005; Scott, 2003).

\subsection{Corporate Organizational Culture Types and Performance}

Cameron and Quinn (2006) crystallized the concept of effectiveness to the culture types by arguing that the criteria of effectiveness most prominent in a hierarchy culture are efficiency, timeliness, smooth functioning, and predictability. They asserted that the dominant operational theory that drives organizational success is control, which foster efficiency and effectiveness. However, in hierarchy organizations, such as government agencies, the dominant operational theory that dictates effectiveness is the adherence to strict rules and regulations. While the underlying premise of hierarchy organizations emphasizes the importance of policies and guidelines, the criteria of effectiveness most prominent in a market culture are achieving goals, outpacing the competition, increasing market share, and acquiring premium levels of financial returns. Further the dominant operational theory that galvanized organizational success is competition which 
creates an impetus for higher levels of productivity and therefore higher levels of effectiveness. Anything short of increasing market share, enhancing revenues, and increasing productivity was seen as failure (Cameron \& Quinn, 2006; Harrigan, 2015; Cadden \& Marshall, 2013).

On the contrary, in the clan culture, the criteria of effectiveness most highly valued include cohesion, high levels of employee morale and satisfaction, human resource development, and teamwork. The operational theory that dominates this culture type is involvement and participation of employees that fosters empowerment and commitment. The literature also found that committed, satisfied employees produce more efficient and effective service (Cameron \& Quinn, 2006; Hooijberg \& Petrock, 2004). Finally, Hooijberg and Petrock (2004) asserted that the adhocracy organizational culture emphasized the importance of new products, creative solutions to problems, cutting-edge technologies, and strategic growth in new market niches as the dominant effective criteria. However, the underlying operational phenomenon is innovation and new ideas, which create new markets, increase customers and new opportunities (Cameron \& Quinn, 2006).

Previous research on the theory of transformational leadership has been focused on comparing its effectiveness with transactional leadership and its effect on individual performance, satisfaction and effectiveness Llies, Judge \& Wagner, 2006). The purpose of this study, however, is to determine if there is any relationship that exists between transformational leadership traits and organizational culture types in improving performance in public sector organizations. The research drew parallels by reviewing literature relating to leadership in the public and private sectors, specifically, the transformational leadership literature that is primarily concerned with the capabilities required to enact organizational performance successfully. In order to achieve this research objective, a comprehensive review and analysis of the work of scholars and practitioners in organizational theories were implemented to examine corporate culture traits.

According to Hooijberg and Petrock (2004), the Competing Values Framework developed by Cameron \& Quinn (2003) identifies two important phenomena among organizations. One dimension represents the control orientation within an organization's structure, focusing on control and flexibility. The other phenomenon reflects the extent to which both the internal and external environments are impacted by the functionality of the organization. The four major quadrants represented by Cameron and Quinn (2006) in Figure 2 have been labeled to distinguish the contradictory or competing variables within the framework, each with its own unique characteristics: The clan quadrant is the upper left, the adhocracy quadrant is in the upper right, the hierarchy quadrant in the lower left, and the market quadrant in the lower right. As Cameron and Quinn (2006) asserted, the dimensions and quadrants appear to be effective in explaining the different orientations, as well as the competing values that characterize human behavior. Further, the robustness of these dimensions and the richness of the resulting quadrants led the researchers to identify each quadrant culture types as hierarchy, market, clan, and adhocracy.

\subsection{The Hierarchy Culture}

Cameron and Quinn (2006) pointed out that one of the earliest pioneers to study organizations is a German sociologist, Max Weber, who studied public sector or government organizations in the early 1900s. The challenge encounter in this era was that public sector organizations failed in their mandates to effectively produce goods and services for a growing complex society (Gorden, 2015). In an attempt to remedy the dysfunctionality encountered with government organizations, Gorden (2015) introduced what Cameron and Quinn (2006) referred to as classical attributes of bureaucracy rules, specializations, meritocracy, hierarchy, separate ownership, impersonality, accountability, which defines the formal characteristics within the internal structures of government organizations. Cameron and Quinn (2006) argued that the characteristics provided a prescriptive impetus for the improvement of organizational effectiveness, and were implemented in organizations whose major challenge was to generate efficient, reliable, smooth-flowing, and predictable output.

\subsection{The Market Culture}

The market culture also became popular during the late 1960s as organizations were confronted with new competitive challenges from rival firms entering into the industrial era. However, unlike the hierarchy culture type, the market approach to organizational culture relied on a fundamentally, different set of assumptions based extensively on the research of Oliver Casimir et. al. (2006), \& Cameron and Quinn (2006), who identified an alternative set of activities that they asserted served as the foundation of organizational effectiveness focusing on the ability of organizations to minimize transactional costs.

\subsection{Clan Culture}

Cameron and Quinn (2006) represented the clan culture type as a family-type organization with a friendly environment in which people like to work and where they share personal thought and opinions about themselves. The clan culture is 
evident in organizations where there is a commonality of understanding among members. It is an organizational environment in which shared values and goals, cohesion, participation and individuality permeates the family like structures. The leaders of the organization, in which the clan culture type is evident, act as mentors and role models (Hooijberg \& Petrock, 2004). Cameron and Quinn (2006) also argued that unlike the hierarchy culture type, in which rules and procedures dictate individual behaviors and the competitive profit center of the market type, the clan culture typified organizations in which teamwork, employee involvement programs, and corporate commitment to employees are heavily emphasized (Cameron \& Quinn, 2006; Hooijberg \& Petrock, 2004).

\subsection{The Adhocracy Culture}

In figure 2, the adhocracy culture type is characterized as a dynamic, entrepreneurial, and creative place to work. However, a major goal of organizations that display adhocracy cultural environment is to foster adaptability, flexibility, and creativity where uncertainty, ambiguity, and information overload are typical (Cameron \& Quinn, 2006). Further, the argument was made that adhocracy cultural environments are short-termed and selected team members strategically join together to accomplish specific projects. However, the major challenge of leaders in these environments is to foster entrepreneurship, creativity, and activity that are technologically advanced (Cameron \& Quinn, 2006; Hooijberg \& Petrock, 2004), and such leaders are considered to be visionary, innovative and task-oriented.

\subsection{Competing Value Framework}

According to Cameron and Quinn (2006) the Organizational Culture Assessment Instrument (OCAI) is based on a theoretical model known as the Competing Values Framework. They further asserted that this framework is fundamentally important in organizing and interpreting a wide variety of organizational phenomena. It must be noted, however, that no one framework is comprehensive, and there are no documented arguments supporting the applicability of one framework over the other in analyzing organizational culture (Denison's \& Mishra, 2005). However, the appropriate framework should be based on empirical evidence; should effectively represent the reality being describe; and should adequately integrate and organize the majority of the dimensions being proposed (Cameron \& Quinn, 2006). The Competing Value Framework will be the methodology used to diagnose and facilitate changes in the culture environments of the public sector organizations in this study. It is a framework that has empirical values, has been tested for both reliability and validity, and helps integrate many of the phenomena argued by various authors (Cameron \& Quinn, 2006). Figure 2 depicts the clan, adhocracy, market and hierarchy culture types which are extrapolated from scholarly literature that explains how different organizational values have become associated with different forms of organizational culture (Cameron \& Quinn, 2006). The quadrants match key management theories about organizational success, approaches to organizational quality, leadership roles, and management skills (Cameron \& Quinn, 2006). Additionally, the dimensions and quadrants in figure 1 explain the different orientations, as well as the competing values, that characterize human behavior. Further, the OCAI is an instrument that enables researchers to diagnose the dominant orientation of the organizations to be studied based on these four culture types. Finally, OCAI also assists the investigator in diagnosing an organization's culture strength, culture type, and cultural congruence (Cameron \& Quinn, 2006; Howard, 2009).

Flexibility and Discretion

\begin{tabular}{|c|c|c|c|}
\hline Internal focus and & Clan & Adhocracy & External Focus and \\
\hline Integration & Hierarchy & Market & Differentiation \\
\hline
\end{tabular}

Figure 2. Organizational culture Framework

\subsection{The Impact of Transformational Leadership Trait, Corporate Organizational Culture Types and Performance on Public and Private Sector Organizations}

This study investigated the relationship between transformational leadership traits and organizational culture types using the Competing Value Framework developed by Cameron and Quinn (2006). The research provided quantitative data to evaluate and analyze the various phenomenons associated with organizational performance and critically examined the impact of leadership styles and organizational culture types which are the two major constructs that dictates organizational performance in the public sector (Rudy et.al. 2008). The assumptions embedded in the objective of the research will add to the body of knowledge; thus, validating the arguments of scholars and theorists that there is a need for further research in the field of organizational studies (Bass \& Avolio, 2002; Cameron \& Quinn, 2006). In formulating a model for studying leadership styles and organizational culture types it was necessary to identify with the pertinent hypotheses that will guide the research questions. Having represented the hypothetical premise, the 
investigation of the link that exists between transformational leadership style and organizational culture type answered the following questions (Cameron \& Quinn, 2006).

The investigation of the relationship that exists between transformational leadership style and organizational culture type as depicted in Figure 3 seeks to answer the following questions:

1. Is there an association between clan culture and a specific leadership style as the dominant leadership style in public sector organizations?

2. Is there an association between adhocracy culture and a specific leadership style as the dominant leadership style within public sector organizations?

3. Is there an association between hierarchy culture and a leadership style as the dominant leadership style within public sector organizations?

4. Is there an association between market culture and a specific leadership style as the dominant leadership style within public sector organizations?

5. Which organizational culture type is directly associated with transformational leadership and is most conducive to organizational performance in public sector organizations?

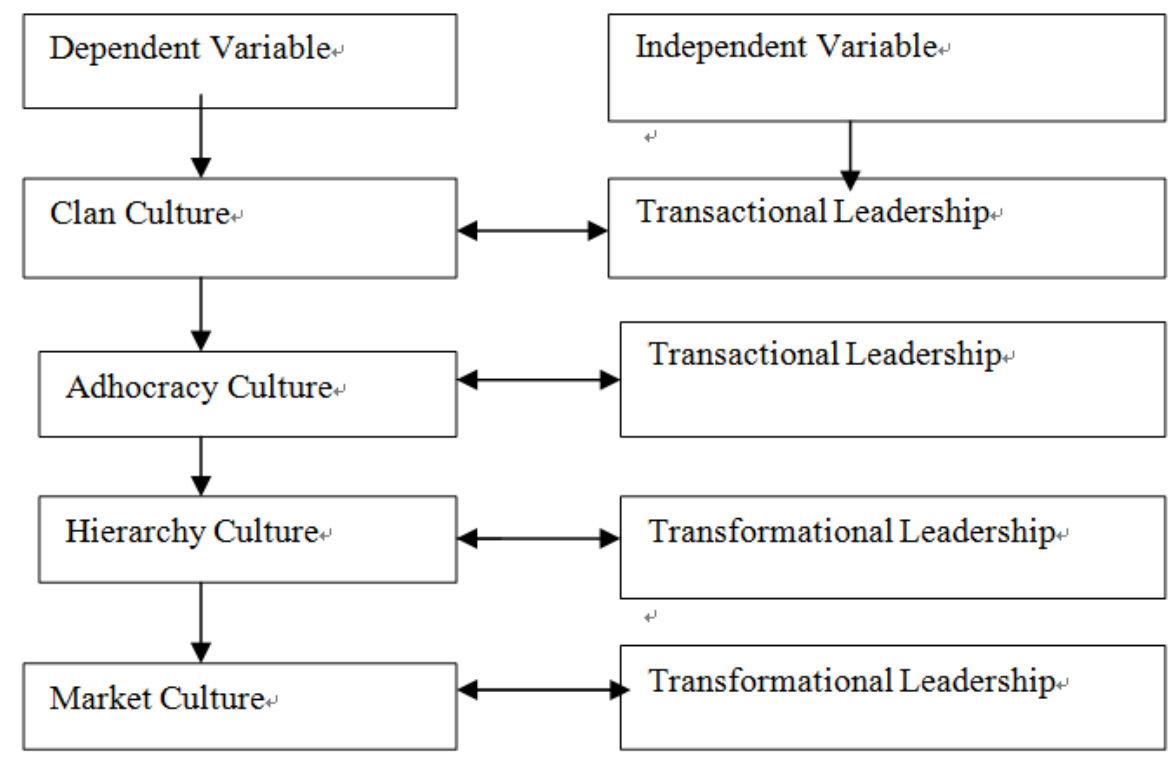

Figure 3. The relationship between variables

The following hypotheses provided a procedural process of the intended research questions of the study.

H1: There is no linear relationship between leadership traits and organizational culture types as defined by the Competing Values Framework.

H2: There is a linear relationship between leadership traits and organizational culture types as defined by the Competing Values Framework.

The Relationship between Transformational Leadership Styles and Organizational Culture Connection in Improving Performance in Public Sector Organizations

Block (2003) produced a seminal research on organizational leadership culture connection, and argued that the leadership and culture are so central to understanding organizations and making them effective that students of organizational behavior cannot afford to be complacent about either one. Additionally, it was argued that current models of organizational performance and change suggest that leadership and organizational culture are central explanatory constructs. Block (2003) conducted a study to explicate the nature of the leadership-organizational culture connection by conducting an ex post facto exploratory investigation of a Private sector organization. The researcher examined two research questions:

Is there a relationship between different types of leadership that may exist within an organization and the presence of specific subcultures? And how does organizational distance impact the leadership-culture connection?

Block (2003), a correlation approach was used to investigate the relationship between leadership styles and organizational culture dynamics. This study took place within a well- established sale and service private company with 900 employees 
across 23 branch locations in North America. He further stated that a survey method was used to collect cultural data, rather than a qualitative analysis which would have restricted the sampling of employees. Block (2003) noted that while the findings of this study reported a significant number of possible causal links, the data are limited to an empirical analysis of the relationship between leadership styles and organizational culture traits. They do not explain its underlying causes; thus future research is needed to further document the explanatory events underlying this organizational dynamic.

Hinkin and Tracey (2013), most of the research on transformational leadership has used a Multifactor Leadership Questionnaire (MLQ) developed by Bass (2003) and Bass and Avolio (2003). Hinkin and Tracey (2013) argued that Bass and Avolio (2003) proposed that transformational leadership is composed of four dimensions or the "four Is": Idealized influence ( II; Charisma), which is based on a follower's respect and admiration for the leader; individualized consideration (IC), the extent to which the leader cares about the individual follower's concerns and developmental needs; intellectual stimulation (IS), the degree to which the leader provides followers with interesting and challenging tasks and encourages them to solve problems in their own ways; and inspirational motivation (IM), which is based on communication of expectations and followers' confidence in the leaders' vision and values. Hinkin and Tracey (2013) conducted a study based on the works of Burns (2003), and Bass and his colleagues (Bass, 2003; Bass \& Avolio, 2002). The purpose of the study was to examine the extent to which the MLQ Form 5X measures the dimensions that it purports to measure in public sector organizations (Hinkin \& Tracey, 2013).

\section{Methodology}

This study utilized a survey instrument in the form of a Multifactor Leadership Questionnaire (MLQ) Form 5X to collect data on leadership behavior, and the Organizational Culture Assessment Instrument (OCAI) to measure organizational culture types. A review of the literature revealed that there are several instruments designed to assess transformational leadership, and the best-known and most rigorously assessed instrument is the Multifactor Leadership Questionnaire (MLQ) Form 5X (Javidan \& Waldman, 2003). Originally designed by Bass (2003), and updated by Bass and Avolio (2002), the MLQ is psychometrically tested for reliability and validity. The argument was made by Bass (2003); Bass and Avolio (2003) and Javidan and Waldman (2003) that the MLQ Form 5X measure the full range of leadership styles. This implies that every leader displays a frequency of both the transformational and transactional factors; but each leader's profile involves more of one and less of the other (Bass, 2003). The MLQ Form 5X instrument was purchased from Mind Garden Inc. and was used in this research with permission. The objective of the selected methodology for the research was to individually test transformational leadership traits and organizational culture types using confirmatory factor analysis of the 39 items. Internal consistency reliabilities were computed for each of the revised factors. Finally, both correlation and regression analysis were computed to examine the relationships among the variable dimensions. The intent was to develop an approach uniquely different from other research to validate the individual variables under investigation.

\subsection{Sample and Procedure}

The surveys were distributed to all full time employees in eight (8) public and private sector organizations of the United States Virgin Islands with braches on St. Thomas, St. Croix and St. John. The participants were given hard copies of the survey to complete with instruction to return the completed copies in sealed envelopes to ensure confidentiality and anonymity. The completed data were keyed into a computer program using both Microsoft Excel and SPSS spread sheets to secure the data and to further preserve anonymity of the responses. The full-time participants of all four agencies received hard copies of a letter asking them to complete the survey by answering questions about their demographics; their organization's leadership and management styles of their immediate supervisors, and their organization's culture. A total of 220 surveys were distributed with 200 returning. Of the 200 that returned, nine (9) were rejected due to insufficient data resulting in 191 usable surveys yielding a response rate of $96 \%$.

\subsection{Measurement}

The literature revealed that the MLQ Form 5X has been used extensively in different organizational settings including the public and private sectors to measure employees' perceptions of leadership behaviors in work environments. Bass and Avolio (2005) asserted that the MLQ Form 5X has been widely used to measure the four dimensions of transformational leadership described as the "Four I's". First is the idealized influence (II) or charisma, which is based on a follower's respect and admiration for the leader. Second is individualized consideration (IC), the extent to which the leader cares about the individual followers' concerns and developmental needs. Next is intellectual stimulation (IS), which is the degree to which the leader provides followers with interesting and challenging tasks and encourages them to solve problems in their own way. Finally, inspirational motivation (IM) which is based on communication of expectations and followers' confidence in the leader's vision and values (Bass \& Avolio, 2005; Bass, 2003; Vigoda-Godot, 2006; Javidan \& Waldman, 2003). To achieve the research objectives, the OCAI scale was combined with the MLQ to achieve a comprehensive assessment of the data. The OCAI used a response scale in which individuals divide 100 points among 
alternatives. This instrument is designed with six, key dimensions to assess the sample received from the respondents. According to Cameron and Quinn (2006), the OCAI dimensions range from dominant characteristics, organizational leadership, management, strategic emphasis, organizational glue, to the criteria for success. Each of the six items can create four possible results which are divided into 100 points, known as an ipsative rating scale. However, the instrument in this study used the Likert scale, in which respondent rate each alternative in each question on a scale of 1 to 5 or 1 to 7 - ranging from strongly agree to strongly disagree. The rating for each of the dimensions was analyzed and summed up. Thus, the results were plotted to determine the strength of each competing culture within the organization. It is argued that each response in the Likert's format create a degree of independence, which ensures objectivity in the research process (Cameron \& Quinn, 2006). The anticipated time it takes for one OCAI questionnaire to be completed was 20 minutes.

\subsection{Analysis of Data}

The data was analyzed in several stages in order to achieve objectivity of the study. The data was examined using descriptive statistics to understand the samples without testing the hypotheses. The age of the respondents ranges from 22 to 55 . The mean age was 42.3 years with a standard deviation of 11.72 . Gender was $34 \%$ male and $65 \%$ female. $98 \%$ of the respondents reported full-time tenure with their agencies with a mean of 9 years. $5 \%$ of the respondents reported tenure with less than 5 years, while $3 \%$ reported tenure with less than 1 year. Although the demographics were incorporated into the data set, they were only used to better understand the sample, and were not used in the analysis of the questionnaires.

Table 1. A comparison of means culture types with leadership traits

\begin{tabular}{lllll}
\hline L. Traits & Clan & Adhocracy & Market & Hierarchal \\
\hline Org. Eff. & 14.17 & 32.5 & 10.83 & $\mathbf{3 7 . 5 0}$ \\
IIB & 14.17 & 32.5 & 10.83 & $\mathbf{3 7 . 5 0}$ \\
IM & 14.72 & 16.72 & 19.22 & $\mathbf{4 3 . 7 2}$ \\
IS & 23.52 & 18.08 & 23.07 & 29.88 \\
IC & 7.50 & 19.16 & 36.25 & 30.42 \\
IIA & 16.67 & 19.00 & 25.83 & 29.17 \\
\hline
\end{tabular}

As shown in table 1, the means cultural types with transformational leadership traits

The results of the sample showed that the respondents were mostly females, well-experienced and have a long tenure with their organizations. An aggregated variance analysis was also conducted on transformational leadership traits to identify those items that were appropriately correlated to Organizational Culture Types using variance procedures. First, the mean score for each of the six transformational leadership scales was calculated, then a comparison of the means was conducted for each item to evaluate the appropriateness of each score (i. e statistically significantly higher on the appropriate definition utilizing t-tests; $\mathrm{p}<0.05$ ) (Flemming, 2009).

\section{Results}

As stated in Table 1, the analysis indicated that the sample size was adequate for assessing the practical significant differences between the means which is consistent with each observation above. The analysis also indicated that the mean scores of Organizational Effectiveness (Org. Eff.) $=37$. 50; Idealized Influence Behavior (IIB) $=37$. 50; and Inspirational Motivation $(\mathrm{IM})=43.75$; seems strongly correlated to Hierarchal Culture types. Intellectual Stimulation (IS); Individualized Consideration (IC) and Idealized Influence Attributes (IIA), reported less significant with 29.88; 30.42; and 29.17 respectively.

A test of correlation was used to measure the relationship between transformational leadership traits and organizational culture types. The MLQ measures leadership constructs (Bass \& Avolio, 2003; Avolio \& Bass, 2003); while the OCAI (Cameron \& Quinn, 2006) measures culture types. The components of the MLQ measuring transformational leadership are: Idealized Influence (Behavior), Inspirational Motivation; Intellectual Stimulation; Individualized Consideration and Idealized Influence (Attributes); Clan Culture; Adhocracy Culture; Market Culture, and Hierarchal Culture formed an overall composite score for transformational leadership and organizational culture. This study utilized the component factor analysis with varimax rotation to measure the correlation between the nine (9) different factors of transformational leadership and culture types consistent with Gordon (2015) and Schimmoeller (2006). The reliable coefficient had an alpha score of .71 and the inter-correlations range from .010 to .823 with a p-value greater that $(p>.05)$ which indicates that the components of transformational leadership and organizational culture types are not independent of each other in this study. The study implemented a regression analysis to test the hypotheses using each culture / leadership variable, and 
to examine the strength of each variable relationship for statistical significant at .05 level of significance using the regression model of SPSS Version 14.0. Transformational leadership traits are dependent on clan organizational culture type as defined by the Competing Value Framework and depicted by the significant (sig) value of .05. The sig. values varies between.009* and .823 level which indicates that there are significant low difference between the relationship of transformational leadership traits and clan culture types at $\mathrm{r}=.197 ; .208 ; 239$; and .100 ; but at $\mathrm{p}=-2.650 ;-.914 ;-1.660$; and 1.383 respectively are significant to the 0.05 level of significance.

Table 2. Clan Leadership Traits Regression

\begin{tabular}{lcllll}
\hline & $\mathrm{R}$ & $\mathrm{R}$ Square & Adj. R Square & $\mathrm{t}$ & sig. \\
\hline Organizational Effectiveness & .016 & .000 & -.005 & .224 & .823 \\
Idealized Influence Behaviour & .052 & .003 & -.008 & .673 & .502 \\
Inspirational Motivation & .197 & .039 & .023 & -2.650 & $.009^{*}$ \\
Intellectual Stimulation & .208 & .043 & .022 & -.914 & .362 \\
Idealized Influence Attributes & .239 & .057 & .032 & -1.660 & .099 \\
Individualized Consideration & .100 & .010 & .005 & 1.383 & .168 \\
\hline
\end{tabular}

As shown in table 2 Clan culture and leadership traits regression

Therefore, the null hypothesis (H1) is rejected. The regression analysis calculates the adjusted $\mathrm{r}$ squared values low at .023; .022; .032; and .005 respectively which is consistent with the findings of Harrigan (2015); Bass and Avolio (2005); Cameron and Quinn (2006), and Selden \& Sowa (2004). This study is the first that analyzed the various constructs of transformational leadership traits and organizational culture types in a cluster approach using quantitative evidence.

Table 3. Adhocracy Leadership Traits Regression

\begin{tabular}{lccccl}
\hline & $\mathrm{R}$ & $\mathrm{R}$ Square & Adj. R Square & $\mathrm{t}$ & sig. \\
\hline Organizational Effectiveness & .055 & .003 & -.002 & -.761 & .448 \\
Idealized Influence Behaviour & .335 & .112 & .103 & -4.803 & $.000^{* *}$ \\
Inspirational Motivation & .362 & .131 & .117 & 2.042 & $.043^{* *}$ \\
Intellectual Stimulation & .382 & .146 & .128 & -1.786 & .076 \\
Idealized Influence Attributes & .457 & .209 & .187 & -3.834 & $.000^{* *}$ \\
Individualized Consideration & .306 & .094 & .089 & -4.425 & $.000^{* *}$ \\
\hline
\end{tabular}

As shown in table 3 Adhocracy culture and transformational leadership traits regression

As illustrated in Table 3, transformational leadership traits are dependent on adhocracy organizational culture type as defined by the Competing Value Framework, and depicted by the significant (sig) value of .05 . The sig. values varies between the $.000^{*}$ level and .448 level which indicates that there are significant low difference between the relationship of transformational leadership traits and adhocracy culture types at $\mathrm{r}=.335 ; .362 ; 382 ; .457$ and .306 ; but at $\mathrm{p}=-4.803$; $2.042 ;-1.786 ;-3.834$, and -4.425 respectively are significant to the 0.05 level of significance. Therefore, the null hypothesis (H1) is rejected. The regression analysis calculates the adjusted $\mathrm{r}$ squared values low at .103; .117; .128; .187; and .089 respectively which is consistent with the findings of Avolio and Bass (2003); Hartog, Jaap \& Koopman (2011), Cameron and Quinn (2006), and Flemming, (2009) who argued that leadership traits are evident in adhocracy organizational culture. This study identified the leadership type as transformational leadership as depicted in Table 3 .

As illustrated in Table 4, transformational leadership traits depend on hierarchal organizational culture type as defined by the Competing Value Framework and depicted by the significant (sig) value of .05. The sig. values varies between.000* and .321 level, which indicates that there are significant low difference between the relationship of transformational leadership traits and hierarchal culture types at $\mathrm{r}=.102 ; .221 ; .274 ; .285$; and .383 , but at $\mathrm{p}=-1.413 ; 2.760 ;-2.302 ; 1.124$, and 3.771 respectively are significant to the 0.05 level of significance. Therefore, the null hypothesis (H1) is rejected. The regression analysis calculates the adjusted $\mathrm{r}$ squared values low at $.005 ; .039 ; .060 ; .062$; and .124 respectively which is consistent with the findings of Avolio and Bass (2003); Flemming, (2009) Cameron and Quinn (2006). Cameron and Quinn (2006) argued that hierarchal organizational culture types can be found in leadership in public sectors organizations. This study adds to the body of knowledge by confirming that leaders in public sector organizations demonstrate strong evidence of transformational leadership traits as stated in Table 4. 
Table 4. Hierarchal Culture Leadership Regression

\begin{tabular}{lccccc}
\hline & $\mathrm{R}$ & $\mathrm{R}$ Square & Adj. R Square & $\mathrm{t}$ & sig. \\
\hline Organizational Effectiveness & 102 & .010 & .005 & -1.413 & .159 \\
Idealized Influence Behaviour & .221 & .049 & .039 & 2.760 & $.006^{* *}$ \\
Inspirational Motivation & .274 & .075 & .060 & -2.302 & $.022^{* *}$ \\
Intellectual Stimulation & .285 & .081 & .062 & 1.124 & .262 \\
Idealized Influence Attributes & .383 & .147 & .124 & 3.771 & $.000^{* *}$ \\
Individualized Consideration & .072 & .005 & .000 & .995 & .321 \\
\hline
\end{tabular}

As shown in Table 4 Hierarchal culture and transformational leadership traits regression

These finding can serve as a model framework in public sector organizations for political leaders that supports matching effective leadership styles with organizational culture types in order to enhance performance. The positive correlation between hierarchy and clan culture was expected with transformational leadership traits. The analysis further reviled that the traits of transformational leadership are idealized influence, inspirational motivation, intellectual stimulation, and individualized consideration. What was unexpected, however, is the strong association with Adhocracy culture which is said to be dynamic, entrepreneurial, and creative place to work; and market culture which is argued to be result oriented, competitive, and goal-oriented (Cameron \& Quinn, 2006; Hooijberg \& Petrock, 2003). Finally, this study corroborated the fact that organizational culture impacts the ability of leaders to improve organization performance as evident by the symbiotic relationship of each construct. The five elements of transformational leadership correlated positively with the four phenomenons of organizational culture types. The analysis of the various component parts of transformational leadership made it possible to evaluate the correlation, which would have otherwise been difficult to evaluate.

\section{Discussion and Proposed Framework}

This study used the Multifactor Leadership Questionnaire (MLQ 5X), and the Organizational Culture Assessment Instrument (OCAI) to collect data from 191 full-time employees in four public sector organizations. The MLQ 5X developed by Bass and Avolio (1994) was used to define leadership traits as idealized influence, inspirational motivation, intellectual stimulation, and individualized consideration. The Competing Value Framework defined by Cameron and Quinn (2004) was implemented to evaluate the organizational culture types. Regression analysis measured the relationship between the independent variable and the dependent variable. It was asserted by Cameron and Quinn (2004) that leadership is related to clan, adhocracy, and Hierarchy cultures. This research presents a model framework exhibited in figure 4 for assessing organizations structur in achieving synergy by effectively identifying transformational leadership traits to organizational culture types. Satisfactory relationship, however, between leadership and culture may be disrupted or altered by economic changes or development; and stakeholders may demand government actions to protect their interest or establish a new equilibrium. Nahavandi (2006) defines a leader as a person who influences individuals and groups within an organization; help them in the establishment of goals; and guide them towards achieving of those goals; thereby allowing them to be effective. In order to be effective, leaders must help the organization maintain internal health and external adaptability. Despite the apparent simplicity of the definitions of leadership, culture and effectiveness, they are difficult concepts to implement. First, culture can affect whom we consider to be an effective leader. Second, organizations rarely provide their leaders with the opportunity to experiment and improve. Third, notwithstanding the many roles that leaders play in an organization, in some situations their impact on group and organizational performance is limited due to unnecessary political pressures. It can be inferred that transformational leaders are role models for other organizational members. Transformational leaders establish and grant the status symbols that are the main artifacts of organizational culture. Followers take their cues from the leaders on what behaviors are and are not acceptable. This research recommends a framework with the four key leadership functions defined as role modeling; the implementation of an objective reward system; the power of the leader to make decisions regarding structure and strategy; and the privileges to make hiring decisions that will shape organizational culture and improve performance.

As depicted in figure 4, this study found organizational effectiveness to be positively correlated with transformational leadership traits, Hierarchy and Clan culture types which are consistent with the research conducted by Yuki (2008), that also found transformational leadership to be positively correlated with satisfaction and leader's effectiveness. There was sufficient evidence, however, to conclude that effectiveness depends on organizational culture types with $p>.05$. Future research is needed to examine the correlation between organizational performance and transformational leadership traits in public organizational environments. Further research is also required to investigate a wider sampling frame and to examine the relationship between leadership and culture behaviors and relevant organizational outcomes Yuki, Donnell \& Taber, 2009. 


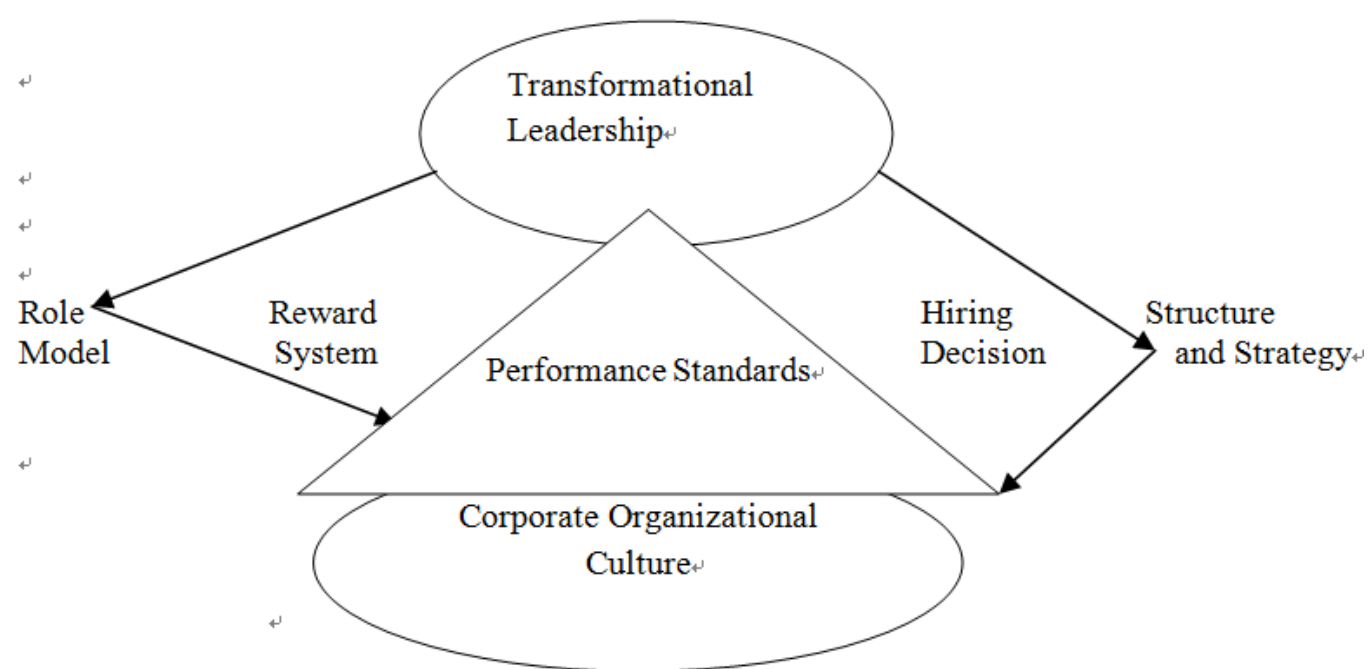

Figure 4. A Transformational Leadership's Framework for Shaping Organizational Culture and Performance

\subsection{Limitation}

The MLQ is only one of many instruments used to evaluate the transformational leadership phenomenon. This instrument, however, has been used extensively by many researchers and has proven to be effective in investigating leadership behaviors in a wide range of organizations Hersey \&Blanchard (2011). Finally, in addition to using the OCAI or the quantitative approach in the form of questionnaires, Cameron and Quinn (2006) asserted that culture can be measured by other means, such as a holistic approach or observation, and a metaphorical or language approach. However, Hartog, Jaap \& Koopman (2011), argued that the OCAI approach is comprehensive and it allows multiple viewpoints to be considered in evaluating the attributes of an organization's culture. Additionally, the scores given to an agency leader may be bias given the perception that leadership in public sector organizations have little continuity after one political term in office, and that a leader may or may not be "welcomed" as a result of one's political affiliations (Hatter \& Bass, 2005; Denison \& Mishra,2005).

\subsection{Research Implications}

There are three important leadership implications that may be derived from this research as it relates to public sector organizations which may contribute to the body of knowledge. First, this study supported the empirical research by Cameron and Quinn (2006) who asserted that hierarchy culture is present in large organizations and government agencies, as evident by standardized procedures, multiple hierarchical levels and an emphasis on rule enforcement. However, this study adds to the body of knowledge by unexpectedly discovering that transformational leadership traits are also embedded in hierarchy, clan, adhocracy and market cultures, thus supporting the assumption that these leaders exhibit visionary and inspirational behaviors. This finding also supports Avolio and Bass (2005); and Naidoo, Coopoo \& Surujlal, 2015) research that successfully argued the case that transformational leaders are effective change agents and followers are more motivated to perform by an inspiring vision from transformational leaders than by the promise of rewards based on performance. Second, from a practical standpoint, it is useful for leaders in public sector organizations to understand the positive correlation between transformational leaders and the hierarchy, clan, adhocracy and market cultures as they relates to organizational performance.

The understanding of the framework, exhibited in figure 4 as proven by this study, may enhance organizational performance by articulating a clear and aggressive strategy which ultimately will lead to productivity and efficiency (Cameron \& Quinn, 2006; Vigado-Gadot, 2006). The implementations of these findings will enable leaders to communicate on where the organizations are going; develop the skills and abilities of subordinates; and encourage innovative problem-solving. Similarly, with this framework, Yin, (2000), conceptualized that it is these leadership behaviors that can truly transform organizations from a static environment to a more efficient and effective workplace. Third, this study has found that transformational leadership to be positively associated with the leader's satisfaction, effectiveness of the leader, role clarity, mission clarity, and openness of communication (Hinkin \& Tracey, 2013). Similarly, Yukl (2008) described transformational leadership as influencing major changes in public sector, organizations' members and building commitment for the organizational objectives. Consistent with these findings, this study should lead us to question whether or not more emphases should be placed on evaluating the mindset of political employees when they are appointed to leadership roles in public sector organizations (Wilderman, et.al. 2000).

\section{Conclusion}

This study hypothesized and proved that transformational leadership traits are dependent on organizational culture types. 
Although this study confirmed that transformational leaders possess the ability to effectively enhance organizational performance, further study is recommended using other leadership styles so that leaders can fully understand and appreciate the appropriate methodology that will effectively enhance performance in specific public sector organizations. This research found that public sector organizations are dominated by hierarchy, clan, adhocracy and market culture types. The eight organizations studied in this research have been characterized by one or more of the four culture types identified by the framework, and they demonstrated a strong correlation to the transformational leadership traits in that these leaders are proficient in organizing, controlling, monitoring, administering, coordinating, and maintaining efficiency. The organizational culture types also demonstrated strong correlations with transformational leadership traits as it relates to team builders, facilitators, nurturers, mentors, and supporters. This study also found organizational effectiveness to be positively correlated with transformational leadership, hierarchy and clan culture which is consistent with the research conducted by Gordon \& DiTomaso (2003) that also found transformational leadership to be positively correlated with satisfaction and leader's effectiveness. Due to the limited number of research in this field, further research is also required to investigate a wider sampling frame and to examine the relationship between leadership and culture behaviors and their relevant organizational outcomes. Based on the findings of the study, it will be appropriate to recommended that organizations operating in a mature culture environment where there are turbulence and uncertainty, understand the link that facilitates organizations effectiveness. Leaders must understand and utilize inspirational motivation, intellectual stimulation, and individualized consideration to create an awareness of change, reinforce and clarify the focus of the organization, and manage the distribution of the scarce recourses in support of the organizations' strategic vision and objectives. While previous research provided data that were unclear as to the synergistic link between transformational leadership traits and organizational culture types, this study attempted to fill the gap between the association of the transformational leadership and organizational culture variables and individually test the traits of leadership and culture to determine where the link exist.

\section{Acknowledgement}

The author understands that collaboration and scholarship are critical for academic advancement. As such, the author would like to acknowledge the contribution of Dr. Barbara Flemming whose review and constant criticism of the manuscript draft, data analysis and population identification enables the completion of this research. The research project would not have being successful without the commitment and support from the leadership of the many government agencies and full time staff. Finally, the author takes full responsibility for collecting, analyzing, and interpreting the results of the data, and any inadvertent errors that may have occurred while completing the report.

\section{References}

Aronson, E. (2001). Integrating leadership styles and ethical perspectives. Canadian Journal of Administrative Sciences, 18(4), 244-256. https://doi.org/10.1111/j.1936-4490.2001.tb00260.x

Avolio, B. J. (2007). Promoting More Integrative Strategies for Leadership Theory-Building. American Psychologist, 62(1), 25-33. https://doi.org/10.1037/0003-066X.62.1.25

Avolio, B. J., Bass, B. M., \& Jung, D. I. (2003). Re-examining the components of transformational and transactional leadership using the multifactor leadership questionnaire. Journal of Occupational \& Organizational Psychology, 72, 441-462. https://doi.org/10.1348/096317999166789

Avolio, B., Waldman, D., \& Yammarino, F. (2004). Leading in the 1990s: The four I's of transformational leadership. Journal of European Industrial Training, 15, 9-16.

Banerij, P., \& Krishnan, V. R. (2000). Ethical preferences of transformational leaders: an empirical investigation. Leadership \& Organizational Development Journal, 21(8), 1-11. https://doi.org/10.1108/01437730010358161

Barbuto, J. E. (2005). Motivation and transformational, charismatic, and transformational leadership: $\quad A \quad$ Test of Antecedents. Journal of Leadership \& Organizational Studies, 11(4), 1-13. https://doi.org/10.1177/107179190501100403

Barney, J. (2016). Organizational culture. Academy of Management Review, 11(3), 656-665. https://doi.org/10.5465/AMR.1986.4306261

Bass, B. M. (2003). Two decades of research and development in transformational leadership. European Journal of Work and Organizational Psychology, 8(1), 9-32. https://doi.org/10.1080/135943299398410

Bass, B. M., \& Avolio B. J. (2005). Improving organizational effectiveness through Transformational leadership. Thousand Oak: Sage Publication.

Bass, B. M., \& Avolio, B. J. (2002). The multifactor leadership questionnaires Form 5X. Center for Leadership Studies, State University of New York, Binghamton, NY. 
Bass, B. M., \& Avolio, B. J. (Spring, 2003). Transformational leadership and organizational culture: Public Administration Quarterly, 17(1), 112-121.

Bass, M., \& Avolio, B. J. (2003). Developing transformational leadership: 1992 and beyond. Journal of European Industrial Training, 14, 21-37.

Blackwell, S. S. (2006). The influence of perceptions of organizational structure \& culture on leadership role requirements: The moderating impact of locus of control \& self-monitoring. Journal of Leadership \& Organizational Studies, 12(4), 1-27.

Block, L. (2003). The relationship between transformational leadership styles and organizational culture connection in improving performance in public sector. The leadership-culture connection: An exploratory investigation. Leadership \& Organization Development Journal, 24(5/6), 318-334. https://doi.org/10.1108/01437730310494293

Brown, E. M. (2007). An examination of the link between organizational culture and performance: A study of three county public health departments (Doctoral dissertation, University of California, Berkeley, 2007). UMI Publication No. AAT 3306035.

Burns, J. M. (2003). Leadership. Transforming Leadership: A New Pursuit of Happiness. New York: Atlantic Monthly Press.

Cadden, C., Marshall, D., \& Coa, G. (2013). Opposites attract: Organizational culture and supply chain performance, Supply Chain Management: An International Journal, 18(1), 86-103. https://doi.org/10.1108/13598541311293203

Cameron, K. S., \& Quinn, R. E. (2006). Diagnosing and changing organizational culture. (Revised Edition). San Francisco: The Jossey-Bass.

Campbell, J. P., \& Freeman, S. J. (2013). Culture congruence, strength and type: Relationships to Effectiveness. Research in Organizational Change and Development, 12(5). Greenwich, CT: JAI Press

Casimir, G., Waldman, D. A., Bartram, T., \& Yang, S. (2006). Trust and the relationship between leadership and follower performance: Opening the Box in Australia and China. Journal of Leadership \& Organizational Studies, 12(3), 1-14. https://doi.org/10.1177/107179190601200305

Cooper, D. R., \& Schindler, P. S. (2006). Business research methods. ( $9^{\text {th }}$ Eds.). New York: McGraw-Hill.

Denison, D. R. (1990). Corporate Culture and Organizational Effectiveness, New York: Wiley.

Denison, D. R., \& Mishra, A. K. (2005). Towards a theory of organizational culture and effectiveness. Organization Science, 6(7), 204-222.

Flemming, P. L. (2009). A study of the relationship between transformational leadership traits and organizational culture types in improving performance in public sector organizations: A Caribbean Perspective: Doctoral dissertation, Capella University. UMI Publication No. 3366452.

Fombrun, C. (2011). Corporate culture, environment, and strategy. Human Resources Management, 22, 139-152. https://doi.org/10.1002/hrm.3930220118

Gordon, G. G., \& DiTomaso, N. (2003), Predicting corporate performance from organizational culture. Journal of Management Studies, (29), 783-798.

Gordon, G.G. (2015). The relationship of corporate culture to industry sector and corporate performance: R. H. Kilman; M. J. Saxton, \& R. Serpa, ( ${ }^{\text {nd }}$ Eds.). Gaining Control of the Corporate Culture, Jossey-Bass, San Francisco, CA, 103-125.

Hambrick, D. C. (2005). Operationalizing the concept of business-level strategy in research. Academy of Management Review, 5(4), 567-576.

Harrigan, K. R. (2015). Strategy formulation in declining industries. Academy of Management Review, 5(4), 599-604.

Hartog, D. N. D., Jaap J. V. M., \& Koopman, P. L. (2011). Transactional versus transformational leadership: An analysis of the MLQ. Journal of Occupational and Organizational Psychology, 1(70), 19-34.

Hater, J. J., \& Bass, B. M. (2005). Superiors' evaluation and subordinates' perceptions of transformational and transactional leadership. Journal of Applied Psychology, 73, 695-702. https://doi.org/10.1037/0021-9010.73.4.695

Hersey, P., \& Blanchard, K. H. (2011). Management of organizational behavior: Utilizing human resources. (5 ${ }^{\text {th }}$ Eds.). Upper Saddle River, N. J.: Pearson Prentice Hall. 
Hinkin, T., \& Tracey, J. (2013). The relevance of charisma for transformational leadership in stable organizations. Journal of Organizational Change Management, 12(2), 105. https://doi.org/10.1108/09534819910263659

Hooijberg, R., \& Petrock, F. (2004). On cultural change: Using the competing value framework to help leaders execute a transformational strategy. Human Resource Management, 32(1), 1-29.

Howard, L. (2009). Validating the competing values model as a representation of organizational cultures. International Journal of Organizational Analysis, (1993-2002), 6(3), 231. https://doi.org/10.1108/eb028886

Howell, J. M., \& Avolio, B. J. (2006). Transformational leadership, transactional leadership, locus of control, and support for innovation: key predictors of consolidated-business-unit performance. Journal of Applied Psychology, (78), 891-902.

Javidan, M., \& Waldman, D. (2003, March). Exploring Charismatic Leadership in the Public Sector: Measurement and Consequences. Public Administration Review, 63(2), 229-242. https://doi.org/10.1111/1540-6210.00282

Kotter, J. P., \& Heskett, J. L. (2004). Corporate Culture and Performance. New York, NY: The Free Press.

Kouzes, J., \& Posner, R. (2002). Leadership the challenge ( $3^{\text {rd }}$ Eds.). San Francisco: The Jossey-Bass.

Lim, B. (2015). Examining the organizational culture and organizational performance link. Leadership and Organization Development Journal, (16), 16-21.

Linnenluecke, M. K., Griffiths, A. (2009). Corporation, culture, and commitment: Motivation and social control in organizations. Journal of World Business, 45(2010), 357-366.

Llies, R., Judge, T., \& Wagner, D. (2006). Making sense of motivational leadership: The trail from transformational leaders to motivated followers. Journal of Leadership \& Organizational Studies, 13(1), 1-22.

Louis, M., Linnenluecke, M. K., Griffiths, A. (2009). Corporate sustainability and organizational culture: An investigator's guide to workplace culture, in organizational culture. Journal of World Business 45 (2010) 357-366.

Nahavandi, A. (2006). The art and science of leadership. ( $4^{\text {th }}$ Eds.). Upper Saddle River, New Jersey: Pearson Prentice Hall.

Naidoo, P., Coopoo, P., \& Surujlal, J. (2015). Perceived leadership styles of sport administrators and the relationship with organizational effectiveness. African Journal for Physical, Health Education, Recreation, 167-181.

Northouse, P. G. (2004). Leadership: Theory and practice. ( $3^{\text {rd }}$ Eds.). Thousand Oak, California: Sage Publication.

Ogbonna, E., \& Harris, L. C. (2000). Leadership style, organizational culture and performance: empirical evidence from UK companies. International Journal of Human Resource Management, 11(1), 766-788. https://doi.org/10.1080/09585190050075114

Parry, W. K. (2012). Enhancing adaptability: leadership strategies to accommodate change in local government setting. Journal of Leadership Studies, 5(4).

Riasi, A., \& Asadzadeh, N. (2015). The relationship between principlas' reward power and their conflict management styles based on Thomas-Kilmann conflict mode instrument. Management Science Letter, 5(6), 611-618. https://doi.org/10.5267/j.msl.2015.4.004

Robbins, S. (2005). Organization theory. Structure, design, and application. $\left(3^{\text {rd }}\right.$ Eds.). Eaglewood, New Jersey: Prentice Hall.

Rowden, R. W. (2002). The strategic role of human resource management in developing a global corporate culture. International Journal of Management, 19(2), 155-160.

Rudd, J., Greenly, G. E., Beaston, A. T., \& Lings, I. N. (2008). Strategic planning and performance: Extending the debate Journal of Business Research, 61(2), 99-108.

Schein, E. (2002). Organizational culture. American Psychologist, 45(2), 109-119. https://doi.org/10.1037/0003-066X.45.2.109

Schimmoeller, L. J. (2006). An empirical investigation of the relationship between organizational culture and leadership styles. Unpublished doctoral dissertation, University of Toronto Canada, UMI 3244423.

Scott, R. W. (2003). Organizations: rational, natural, and open system ( $5^{\text {th }}$ Eds.). New Jersey: Upper Saddle River.

Scott, W. R., \& Davis, G. F. (2007). Organizations and Organizing: Rational, Natural, and Open Systems, Pearson/Prentice Hall, Upper Saddle River, NJ.

Selden, S. C., \& Sowa, J. E. (2004). Testing a Multi-Dimensional Model of Organizational Performance: Prospects and 
Problems. Journal of Public Administration Research and Theory, 14(3), 395-416. https://doi.org/10.1093/jopart/muh025

Shilbury, D., \& Anne, M. K. (2006). A Study of Organizational Effectiveness for National Olympic Sporting Organizations. Nonprofit and Voluntary Sector Quarterly, 35(1), 5-38. https://doi.org/10.1177/0899764005279512

Tucker, B. A., \& Russell, R. F. (2004). The influence of the transformational leader. Journal of Leadership \& Organizational Studies, 10(4), 103-111. https://doi.org/10.1177/107179190401000408

Vigoda-Gadot, E. (2006). Leadership Style, Organizational politics, and employee's performance: An empirical examination of two competing models. Emerald group Publishing Limited, 36(5), 661-683.

Wilderom, C. P. M., Glunk, U., \& Maslowski, R. (2000), Organizational culture as a predictor of organizational performance, in Ashkanasy, N. M., Wilderom, C. P. M., Peterson, M. F. (Eds.). Organizational Culture and Climate, Sage, Thousand Oaks, CA, 193-209.

Yin, R. (2003). Case study research design and methods ( $3^{\text {rd }}$ Eds.). Thousand Oak: Sage Publication.

Yuki, G. (2002). Leadership in organizations. ( $5^{\text {th }}$ Eds.). Upper Saddle River, NJ: Prentice Hall.

Yukl, G. (2008). Leadership in organizations ( $3^{\text {rd }}$ Eds.). Englewood Cliffs, NJ: Prentice-Hall

Yukl, G., O'Donnell, M., and T. Taber. (2009). Influence of leader behaviors on the leader-member exchange relationship. Journal of Managerial Psychology, 24(4), 289-299. https://doi.org/10.1108/02683940910952697

\section{Copyrights}

Copyright for this article is retained by the author(s), with first publication rights granted to the journal.

This is an open-access article distributed under the terms and conditions of the Creative Commons Attribution license which permits unrestricted use, distribution, and reproduction in any medium, provided the original work is properly cited. 